\title{
Powdery Mildew of Crenate Deutzia Caused by Erysiphe deutziae in Korea
}

\author{
Mi-Jeong Park ${ }^{1}$, Young-Joon Choi ${ }^{1,3}$, Seung-Beom Hong ${ }^{2}$ and Hyeon-Dong Shin ${ }^{1 *}$ \\ ${ }^{1}$ Division of Environmental Science and Ecological Engineering, Korea University, Seoul 136-701, Korea \\ ${ }^{2}$ Korean Agricultural Culture Collection, National Agrobiodiversity Center, Suwon 441-853, Korea \\ ${ }^{3}$ Department of Organismic and Evolutionary Biology, Harvard University, Cambridge, MA 02138, USA \\ (Received on February 16, 2010; Accepted on March 21, 2010)
}

Crenate deutzia (Deutzia crenata Sieb. \& Zucc.) is a common ornamental shrub belonging to the Hydrangeaceae. In July 2007, powdery mildew infections were first noticed in a garden of National Agrobiodiversity Center, Suwon, Korea. Powdery mildew lesions on leaves and non-lignified stems were conspicuous, especially when growing in the shade (Fig. 1A). The leaves exhibited chlorotic circular patches, sometimes forming reddish discolorations (Fig. 1B). Production of chasmothecia was found starting from September and continued into November. Voucher specimens are kept at Korea University (KUS-F24694, F24779).

White superficial colonies developed with abundant sporulation. Hyphal appressoria were lobed, single or opposite in pairs. Conidiophores were $55-98 \times 7.5-10 \mu \mathrm{m}$, composed of 3-4 cells, straight or slightly flexuous at the base, and producing conidia singly. Conidia were ellipsoid to barrel-shaped, 25-34×12.5-16.5 $\mu \mathrm{m}$, devoid of conspicuous fibrosin bodies, and producing perihilar germ tubes. First formed conidia were rounded at the apex and subtruncate at the base. Chasmothecia were $90-135 \mu \mathrm{m}$ in diam.,

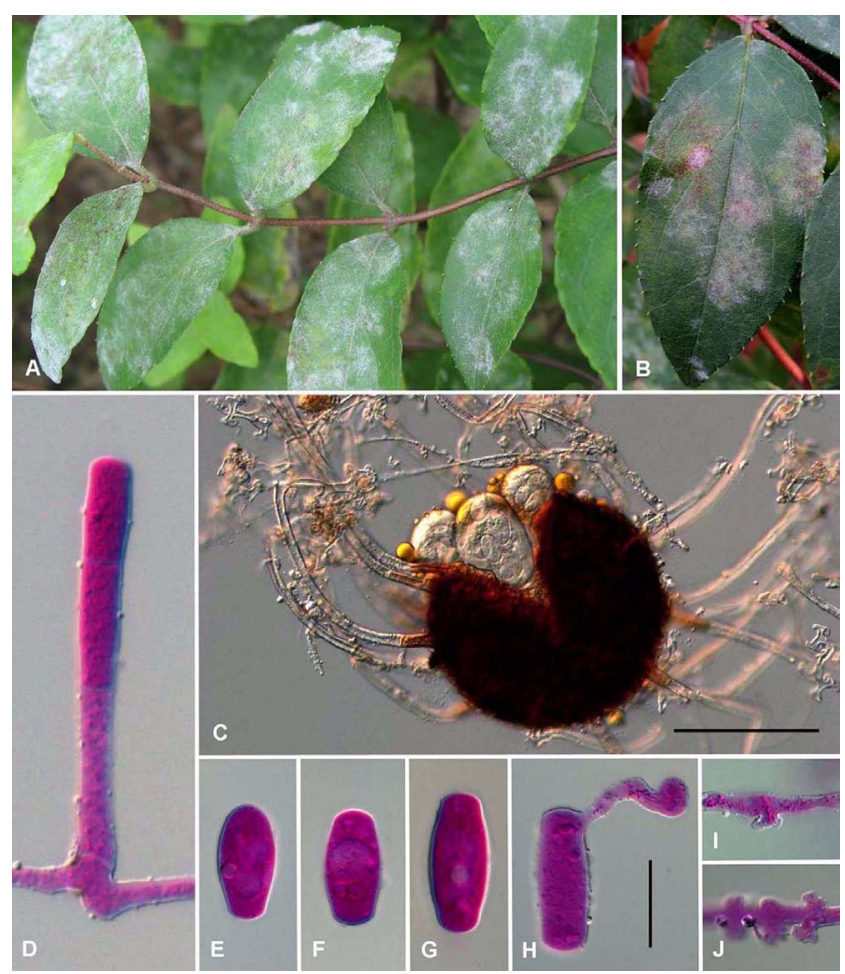

Fig. 1. Powdery mildew symptoms and Erysiphe deutziae on Deutzia crenata. (A) Infections on the young shoot. (B) Reddish discoloration of the lesions. (C) Chasmothecium producing several asci with 6-8 ascospores each. (D) Conidiophore. (E) First formed conidium. (F\&G) Conidia. (H) Germinating conidium. (I\&J) Hyphal appressoria. Each structure in D-J was stained with lactofuchsin. Bar $=100 \mu \mathrm{m}$ for $\mathrm{C}$ and 20 $\mu \mathrm{m}$ for D-J. blackish brown, depressed globose. Appendages were about 8-14 in number, substraight to mildly bent, 4-5 times dichotomously branched, apex recurved, 1-3-septate. Asci were 3-6 per chasmothecium, 42-52 $\times 36-45 \mu \mathrm{m}, 6-8$-spored. Ascospores were oval, $18-$ $22 \times 12.5-15 \mu \mathrm{m}$ (Fig. 1C-J). The observations were in full agreement with previous records of Erysiphe deutziae (Bunkina) U. Braun \& S. Takam. (Nomura, 1997; Bolay et al., 2005).

To confirm the identity of the fungus, the complete ITS region of rDNA from KUS-F24694 was amplified with primers ITS5 and P3 as described by Takamatsu et al. (2009) and directly sequenced. The resulting sequence of $560 \mathrm{bp}$ was deposited in GenBank (GU196146). Phylogenetic analysis was performed using MEGA4 with neighbor-joining method (using Tajima-Nei model). The Korean isolate showed $100 \%$ similarity with two sequences of $E$. deutziae found on D. crenata and D. scabra Thunb. from the UK (DQ861917 and DQ861918, respectively). Therefore, the sequence analysis verified the pathogen to be E. deutziae.

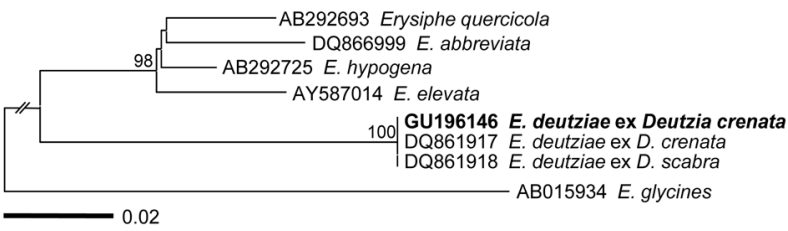

Fig. 2. Phylogenetic relationship between Erysiphe deutziae on Deutzia and related Erysiphe species, inferred by neighbor-joining method using the ITS rDNA region. Numbers above the branches represent the bootstrap values. Bar $=$ Number of nucleotide substitutions per site.

Erysiphe deutziae is the only powdery mildew fungus known from Deutzia spp. This fungus has been recorded from Russian Far East and Japan (Nomura, 1997) and recently from Europe with new epidemic spread in France, Germany, Poland, Switzerland and the UK (Bolay et al., 2005; Denton and Henricot, 2007) on several species of Deutzia. There has been no previous record of $E$. deutziae from Korea, where several native and introduced species of Deutzia are growing. This is the first record of this fungus as well as its host plant in Korea.

\section{References}

Bolay, A., Braun, U., Delhay, R., Kummer, V., Piatek, M. and Wolczanska, A. 2005. Erysiphe deutziae - a new epidemic spread in Europe. Cryptog. Mycol. 26:293-298.

Denton, G. and Henricot, B. 2007. First report of powdery mildew on Deutzia spp. in the UK. Plant Pathol. 56:353.

Nomura, Y. 1997. Taxonomical Study of Erysiphaceae of Japan. Yokendo Ltd., Tokyo, Japan. 281 pp. (in Japanese)

Takamatsu, S., Heluta, V., Havrylenko, M. and Divarangkoon, R. 2009. Four powdery mildew species with catenate conidia infect Galium: molecular and morphological evidence. Mycol. Res. 113:117-129.

\footnotetext{
*Corresponding author (hdshin@korea.ac.kr)
} 